\title{
CACIQUES: LEGITIMIDAD Y VALIDACIÓN INSTITUCIONAL EN CHILE CENTRAL COLONIAL. IMPLICANCIAS Y ESTRATEGIAS PARA SU CONTINUIDAD
}

\author{
CACIQUES: LEGITIMACY AND INSTITUTIONAL VALIDATION IN COLONIAL \\ CENTRAL CHILE. IMPLICATIONS AND STRATEGIES FOR CONTINUITY.
}

\author{
Macarena Cordero Fernández*
}

\begin{abstract}
El objetivo de este artículo es demostrar que los caciques de la zona central de Chile fueron legítimos en la medida que su nombramiento estuviese de acuerdo con la costumbre indígena, el que una vez validado por la Corona, permitía que el cacique ejerciera el "gobierno" de su pueblo. De esta forma confluyeron el derecho indígena y el derecho hispano, cuestión que respondió a la estrategia imperial de contar con mediadores culturales y agentes de control social que coadyuvaran a las autoridades estatales y eclesiásticas en el proceso de colonización.
\end{abstract}

Palabras claves: Cacique, costumbre indígena, prácticas judiciales.

The purpose of this article is to demonstrate that the caciques of the central zone of Chile were legitimate to the extent that their appointments were under the indigenous custom, which, once validated by the Crown, allowed the caciques to exercise the "government" of their people. In this way, indigenous law and Hispanic law came together, an issue that responded to the imperial strategy of having cultural mediators and social control agents to assist state and ecclesiastical authorities in the colonization process.

Key words: Cacique, indigenous custom, judicial practices.

\section{Introducción}

Las prácticas judiciales ${ }^{1}$ realizadas por los caciques son de variada importancia para esta investigación, porque mediante su conocimiento no solo es posible establecer la manera en que se aproximan estos sujetos al derecho hispano, sino también la forma en que ellos lo han recibido y adaptado a sus propios sistemas culturales, y de qué manera las tradiciones indígenas influyeron en el derecho indiano (Pietschmann 1990). Asimismo, porque la continuidad de la institución de cacicazgo a lo largo de todo el período colonial significa "la pervivencia de una particularidad jurídica indígena... moldeada por una legislación que si bien trata de integrarla en el sistema del derecho indiano, respeta en lo fundamental la tradición jurídica indígena relacionada con tales conceptos" (Pietschmann 1990). En efecto, la inclusión del concepto de cacique en el derecho indiano conlleva, necesariamente, la reapropiación por parte de los conquistadores de las implicancias de la institución en comento.

Estas prácticas nos permiten, además, poder determinar cómo estaban constituidos los cacicazgos en la zona central de Chile, asunto aún no del todo analizado por la historiografía. Es más, la reflexión en torno a esta categoría analítica cobra mayor interés si pensamos que se trata de una de las instituciones sociales y políticas indígenas de mayor importancia en el período colonial. Lo anterior, porque permite entender y descifrar si la política y la legislación indiana estuvieron en consonancia o no con la configuración de las comunidades indígenas, luego de la desestructuración provocada por la conquista ${ }^{2}$.

No obstante, este estudio se ha enfrentado a varios problemas o dificultades metodológicas. Entre ellos, determinar qué se entiende por "cacique", cuestión que es relevante, ya que los registros utilizados corresponden a procesos judiciales seguidos ante diversos foros de justicia del Reino de Chile, en los que se consigna tanto el término "cacique" como los de "cacique interino y cacique gobernador" $y$, asimismo, el término "mandón". Hacer esta distinción es relevante porque nos permitirá dilucidar si para los siglos XVII y XVIII el cacique fue tal por linaje, por méritos y habilidades, o lo fue gracias a un sistema mixto, vale decir, linaje y méritos. Asimismo, porque mediante esta distinción es posible

* Instituto de Historia, Universidad de los Andes. Santiago, Chile. Correo electrónico: maca.cordero@yahoo.es 
determinar los derechos, deberes y facultades, entre otros, de los diversos tipos de autoridades indígenas.

A su vez, la dificultad de la investigación es tal, porque recordemos que la legislación indiana asimiló el término "cacique" al de "mayorazgo", lo que supone un estatuto jurídico específico, cuestión que implica reconocer un estatus especial que conlleva la exención de tributos y servicios personales, entre otros ${ }^{3}$. En todo caso, quedará en esta oportunidad en suspenso establecer hasta qué punto tal convergencia de conceptos se dio en la práctica en la zona central chilena.

Además, el análisis se hace complejo debido principalmente al hecho de que las fuentes de que disponemos son del período colonial: crónicas, documentos notariales, expedientes judiciales, entre otros. Esta cuestión dificulta determinar en qué medida la institución del cacicazgo se condice con la costumbre indígena prehispana ${ }^{4}$, y, más aún, establecer las continuidades y discontinuidades del cacicazgo entre el período precolombino y el colonial, que, analizadas, pueden contribuir a explicar hasta qué grado la institución del cacicazgo se enriqueció de la cultura jurídica hispana, y viceversa.

El presente avance de investigación tiene por objeto establecer que los caciques de las zonas comprendidas entre Copiapó y el Maule en los siglos XVII, y especialmente en el XVIII, lo fueron en general por linaje, sin perjuicio de que se constató la existencia de caciques elegidos por méritos. Asimismo, que tal designación no era suficiente si es que no era validada por la Corona, cuestión fundamental, debido principalmente al estatus que otorgaba el cargo de cacique, el que implicó ciertas facultades, derechos y obligaciones, reconocidos estratégicamente por las autoridades coloniales, toda vez que mediante la conservación de la institución del cacicazgo fue posible mantener una continuidad histórica y política que implicó avanzar en el control social y articulación de las comunidades indígenas en el nuevo escenario originado por efecto de la colonización.

\section{El cacique}

El Diccionario de la Real Academia Española entiende por cacique:

"Señor de vassallos, o el Superior en la Província o Pueblo de los Indios: y aunque en muchas partes de las Indias tienen otros nombres, segun sus idiomas, los Españoles los llaman a todos Cacíques, que parece lo tomaron de las Islas de Barlovento, que fueron las primeras que se conquistaron" (Diccionario de la Real Academia Española, 1729, II).

Así, la voz "cacique" se extendió por todo el continente, dejando atrás los términos utilizados por cada etnia en específico ${ }^{5}$, entendiéndose conceptualmente como los jefes locales de una comunidad indígena, pudiendo estar en tal cargo o posición debido a las diversas costumbres de los distintos pueblos, o bien por influencia de la legislación española tendiente a una homogeneización político-cultural. Vistas, así las cosas, se trata de una autoridad. No obstante, es posible preguntarnos si son caciques porque desde el período precolombino existió tal cargo, o fue a partir de la indianización ${ }^{6}$ que se extiende esta institución a todo el mundo americano. Lo anterior es relevante en cuanto que el estatus de "cacique" determina su posición al interior de una comunidad, debido principalmente a que su reconocimiento por la legislación indiana conllevó una situación de privilegio. Pero aún más, conservar la institución de cacique implicó para la Corona contar con mediadores entre ella y los súbditos indígenas, los que debían lograr, por medio de negociaciones, consensos en la aceptación de las nuevas imposiciones establecidas desde la Península ${ }^{7}$. Seguidamente, los caciques validados por la Corona tendrían por misión coadyuvar en el control social de las zonas rurales ${ }^{8}$, siempre tan carentes de autoridades reales en el Chile central (Cordero 2014: 143; Cordero 2017)

A su vez, es relevante determinar si el "cacique" es además "gobernador", entendiendo este último término en el sentido de quien, efectivamente ejerciendo el poder, dirige y gobierna un pueblo. La hipótesis general para el mundo americano es que los caciques son tales por linaje o elección de su pueblo, según la costumbre étnica ${ }^{10}$. Pero si además confluye en su persona la calidad de "gobernador", ejerce funciones de gobierno ${ }^{11}$. Así, estamos en presencia de un cacique gobernador cuando este, además de su estatus de cacique, es considerado por la autoridad competente-corregidores o subdelegados, luego de la introducción de las reformas borbónicas- para ejercer el gobierno de la comunidad, esto es, cobrar tributos, administrar las cajas y tierras comunales, entre otras ${ }^{12}$. Tal es el caso de Pascual Quchipoco, 
cacique gobernador del pueblo de Lampa "...y encargado de todos los inmediatos a esta capital..." (AHNCH, RA, 2344, 4, 36, 1817: 107). Se trata entonces del cacique del pueblo de Lampa, pero que, a su vez, es gobernador de su localidad natal y de otros pueblos cercanos, lo que conllevó que bajo su autoridad estuvieran no solo las personas que habitaban su cacicazgo, sino que, además, las de otros pueblos que contaban o no con cacique, entre ellos Choapa, lejano a 80 leguas de Lampa.

Si bien se trató de dos cargos -cacique y gobernador $^{13}$-, generalmente estuvieron unidos en una sola persona ${ }^{14}$ en las zonas rurales de Chile central, lo que significó que la Corona reconoció las costumbres jurídicas indígenas en relación con la designación de caciques -cuestión estratégica que facilitó la conquista-, y además dicha unión significó que la relación de mando sobre una comunidad recayera en el cacique. Ello porque el monarca lo nombró gobernador. Así, si bien los caciques pueden ser tales por la costumbre indígena, además son impuestos por la Corona, en la medida en que se les concede la calidad de gobernador ${ }^{15}$. En tal sentido, los registros analizados dan cuenta de que lo esperable era que el cacique fuera gobernador $\mathrm{y}$, asimismo, lo complejo que podía ser la ausencia de este tanto para el pueblo como para los encomenderos:

\begin{abstract}
"Acaese estar por la presente referida encomienda sin cacique que gobierne a los indios que residen en dicho pueblo de rapel respecto de estar ausente el cacique propietario llamado Juan de Dios... ignorándose asimismo si el susodicho vive o se ha muerto. Donde sea su paradero; y porque todos los Indios del expresado Pueblo con respecto a la carencia de gobierno que tienen, y en virtud del perjuicio que se les origina han venido todos conforme de común acuerdo y consentimiento en nombrar a Blas Chuli..." (AHNCH, CG, $531,10,92$ )
\end{abstract}

Por otra parte, hay registros documentales que indican que en Chile central hubo caciques interinos, es decir, aquellos que tenían relaciones de parentesco con el anterior cacique; o bien que estaban en ese cargo por la incapacidad del llamado naturalmente a suceder el cacicazgo ${ }^{16}$, o lo hacían mientras pendía la ratificación de un cacique titular, como era la situación de Julián Paquilicuima, quien solicitó el reconocimiento de su pretensión a cacique de Huasco Alto a la Real Audiencia, pero, además, pidió que se le nombrase cacique interino mientras se resolvía lo principal, cuestión que fue acogida por la Audiencia de Santiago (AHNCH, RA, 1949, 2, 93).

Pues bien, la documentación relativa a la zona central del Reino de Chile nos induce a sostener que la legislación para Indias reconoció las costumbres indígenas para el nombramiento de caciques. Costumbres que no podemos aseverar que sean de carácter prehispánico, debido a la falta de registros al respecto. En todo caso, se permitió la autogeneración de autoridades, aunque, insistimos, ello debió obedecer a una estrategia peninsular cuyo propósito era conquistar de manera más fácil y eficiente a la población indígena, por medio de un intermediario legítimo y válido. Legítimo en cuanto lo es de acuerdo con el derecho indígena y su tradición, y válido porque la Corona conserva y reconoce esa tradición ${ }^{17}$. Asimismo, esto provocó que los caciques gozaran de un mayor estatus en cuanto representan al rey al interior de sus pueblos, y si además eran gobernadores -lo que se concreta mediante el acto judicial de nombramiento como propietario de un cacicazgo-, percibían un porcentaje de la recaudación de tributos indígenas como, también, el uso y goce de una determinada cantidad de tierras, que equivalía al doble de los demás indios ${ }^{18}$.

Ahora bien, su estatus puede deberse a su linaje; en tal caso se refiere al reconocimiento de la legislación española a la costumbre indígena de nombrar como caciques a quienes tenían los vínculos de parentesco para ello ${ }^{19}$. Estos vínculos pueden ser de muy variada índole; por ejemplo, ser el hijo primogénito ${ }^{20}$. O bien uno de los hijos varones del cacique que ha demostrado a la comunidad habilidades y aptitudes para asumir el cargo ${ }^{21}$, sin perjuicio de que también haya habido caciques elegidos ${ }^{22}$, de acuerdo con sus usos, por sus méritos y capacidades especiales a favor del pueblo ${ }^{23}$.

Es admisible preguntarnos, en este contexto, ¿qué se entiende por costumbre? Sebastián de Covarrubias y el Diccionario de la Real Academia Española indican al respecto que: La costumbre hace ley; entiéndase cuando no hay ley en contrario, ni repugna a la razón y justicia (Tesoro de la lengua Castellana 1611: 245). A su vez, el Diccionario de la Real Academia Española hace alusión a la acepción de "costumbre inmemorial": "La que se ha usado inconcusamente, sin haber memoria de 
haberse ejecutado acto contrario a ella". Concepto recogido en la Recopilación de Leyes de los Reynos de las Indias en el Libro 5, título 7, ley 1, al indicar: "Por testigos que depongan en la forma que el derecho quiere, del tenor de las dichas escrituras, y asimismo por costumbre inmemorial".

Tales distinciones en lo que toca al término costumbre son relevantes, ya que la Corona reconoció la costumbre indígena de autogenerar caciques, que evidentemente debían estar en consonancia con la razón y justicia. Esta cuestión fue así, porque se validó el sistema de adquisición del estatus de cacique por linaje, ya que no contradecía las normas que regían al mundo cristiano. A su vez, se deduce e interpreta de ello un reconocimiento por parte de la Corona de aquellas costumbres indígenas justas o razonables, las que fueron incorporadas a la legislación indiana, es decir, pasaron a constituir parte del derecho indiano. Entre ellas, que el cacique lo sea por méritos u otros actos que para la comunidad tengan relevancia.

Pero no era suficiente que la costumbre fuese justa, razonable o moralmente intachable. Además, debía ser inmemorial, es decir, tal como lo indica la Recopilación, ha de ser "asentada, fija, sin alteración ni prohibición en contrario y con muchos actos del mismo género que la confirmen" (Recopilación 1681: 2.2.21) En buenas cuentas, la Corona reconoció el cacicazgo por linaje o por méritos, porque comprendió que se trataba de costumbres asentadas entre los indígenas, dicho de otro modo, que constituía una tradición.

Lo anterior se acreditaba mediante una actuación judicial ante el gobernador, virrey o Real Audiencia, autoridades que contaron con la competencia para ello, de acuerdo con la Legislación de Indias. En lo relativo a las zonas comprendidas en la zona central del Reino de Chile, fue la Real Audiencia de Santiago la que validó la titularidad de los cacicazgos. En efecto, mediante un procedimiento judicial fue esta institución indiana la llamada a refrendar la propiedad del estatus de cacique. Así se consigna en diversas actuaciones judiciales indígenas al indicar, por ejemplo:

“...Santa Rosa de Huasco 5 de enero de 1789: Remítase esta representación a la Real Audiencia de este reyno, a quien compete providenciar sobre su contenido, encargándole, cuide hacer despachar con preferencia la declaración del derecho a este cacicazgo, por falta que hace su ejercicio en el gobierno de los naturales de su dependencia..." (AHNCH, RA, $1697,6,16)^{24}$

Se trata de la petición que hizo Julián Paquilicuima, hijo legítimo del cacique don Ramón Paquilicuima y de Bartolina Basan, el que reclamaba para sí el cacicazgo de Huasco Alto, al que tenía derecho por linaje. En efecto, diez años antes, en 1779, el cacique Ramón Paquilicuima había muerto. En el ínterin, y en ausencia de cacique legítimo “...se nombró por mandón a Don Gregorio Saguas del gremio de Huasco Bajo..." (AHNCH, RA, 1697, 6, 16). Esta situación era inaceptable para Julián Paquilicuima porque Gregorio Saguas “...desde luego no puede existir en dicho pueblo tal mandón, así por ser de distinto gremio; como por tocarme, y pertenecerme el título de cacique como hijo legítimo del finado..." (AHNCH, RA, 1697, 6, 190).

El futuro cacique de Huasco Alto daba cuenta de que don Gregorio Saguas no podía ejercer de "mandón", pues era de otro "gremio", esto es, de acuerdo con lo que indica el Diccionario de la Real Academia Española, “...en su riguroso sentido significa el regazo..." (Diccionario de la Real Academia Española 1734: IV) ${ }^{25}$, pero además alude al concepto de "un grupo de personas que están unidas entre sí por nexos comunes que los identifica como una comunidad o grupo". Así, lo que estaba haciendo notar el postulante era que don Gregorio Saguas no tenía linaje para ser cacique, lo que implicaba, además, que difícilmente podía ser su líder. A su vez, que no era causa suficiente tener vínculos de parentesco con el anterior cacique para ser reconocido como tal; era importante, además, estar vinculado a la comunidad; en definitiva, compartir un mismo sistema cultural con la población que integraba el pueblo.

Por lo anterior, Julián Paquilicuima solicitó se le reconociera su estatus, y que mientras probaba su linaje le fuese dado en interinato el cacicazgo. Aún más, estratégicamente Paquilicuima sindicó a Gregorio Saguas como "mandón”, y no como cacique interino. Ello es relevante en cuanto a que la figura del "mandón", de acuerdo con el Tesoro de la Lengua Castellana, se identifica con "...término bárbaro, el que manda que hagan muchas cosas que hagan otros" (Tesoro de la lengua Castellana 1611: 536). A su vez, el Diccionario de la Real Academia Española hace alusión al “... que manda 
muchas cosas, con demasiado imperio y autoridad, y en más de lo que le toca" (Diccionario de la Real Academia Española 1726: IV). Se trata entonces de aquel que dirige un grupo de indígenas, aunque con carácter ilegítimo, porque se atribuye funciones y competencias de las que bajo otras circunstancias carecería $^{26}$.

Se evidencia, en las palabras de Julián Paquilicuima, que el cacique de esa localidad debía serlo por linaje con el anterior, lo que seguramente respondía a una costumbre inmemorial, aunque el expediente no lo consigna. Pero, a su vez, debía estar vinculado con la comunidad o "gremio", pues de lo contrario no era visto como legítimo por quienes serían sus gobernados ${ }^{27}$. Es más, el aspirante a cacique presentó su demanda al Gobernador Ambrosio O'Higgins, quien en visita por la ciudad de Vallenar procedió a recorrer las zonas rurales. Bajo tal coyuntura es que Paquilicuima hizo ver al Gobernador los derechos que tenía. No obstante, O'Higgins se excusó de conocer, pues la costumbre en el Reino de Chile era que "fuesen conocidos estos asuntos por la Real Audiencia"; de ahí que remitiera los antecedentes, toda vez que es esta institución "....a quien compete providenciar sobre su contenido....". El Gobernador agregaba:

"Dirijo a US. La adjunta solicitud de don Julián Paquilicuima, para que en conformidad a las leyes, y de la autoridad privativa que por ellas compete a ese tribunal providencie lo que estime conveniente a poder declarar con posible anticipación el derecho a ese cacicazgo, en el concepto que falta de ejercicio de este cargo está causando perjuicios considerables a los naturales de su dependencia que echan menos, y reclaman con tesón las ventajas de su protección, y su gobierno..." (AHNCH, RA, 1697, 6, 191).

El Gobernador de Chile hace alusión directamente al hecho de que el cacique no solo lo es por linaje, sino que además debe contar con el beneplácito de su comunidad, el que puede deberse a méritos, reconocimientos de sus paisanos u otros, que impliquen respeto y liderazgo, situación que no se presentaba en el caso del mandón don Gregorio.

La Audiencia de Santiago, al conocer los antecedentes, procedió a dar una Real provisión al subdelegado de Santa Rosa de Huasco para que en dicho pueblo fijase los edictos convocatorios anunciando la vacante de cacicazgo, por el término de 15 días. Durante ese plazo los interesados que tuviesen el derecho a reclamar el cacicazgo por “...sus acciones o entroncamiento con el último poseedor" debían concurrir presentando antecedentes que dieran fe de la existencia del derecho. Mientras tanto, se concedía el cacicazgo interino a su principal interesado, don Julián.

\section{Las justicias y el reconocimiento del cacique}

Queda de manifiesto en los diversos expedientes judiciales que, producida la vacancia de un cacicazgo -fuese por muerte, ausencia o destitución del cacique ${ }^{28}$-, la Real Audiencia ordenaba que se publicara en lugares públicos del pueblo los edictos convocatorios que anunciaban "la vacancia del cacicazgo", con la finalidad de que en el plazo de 15 días los interesados concurrieran ante el corregidor o subdelegado, quienes actuando como justicias solo debían recibir a los interesados y admitir las informaciones con las que acreditaran su derecho al cacicazgo. Una vez presentados los documentos y testimonios, debían remitirlos en sobre cerrado y sellado a la Audiencia de Santiago.

Es durante este término de emplazamiento cuando se revela de qué manera los indígenas recibieron y adoptaron el derecho hispano. Lo anterior porque los postulantes a caciques presentaban las actas de bautismo ${ }^{29}$, mediante estas acreditaban su calidad de hijo legítimo del cacique anterior, o su parentesco, en caso de que no existiera descendencia, como también los antecedentes probatorios necesarios de todos aquellos postulantes que consideraban que tenían la idoneidad y méritos suficientes como para asumir el cargo. Asimismo, concurrían los testigos del o los pretendientes, con la finalidad de declarar que los conocían, de su buen trato y que contaban con los requisitos para ser caciques.

En buenas cuentas, los postulantes al estatus de cacique, aun cuando fuesen legítimos herederos, sabían que para alcanzar el cargo debían encauzar sus acciones por medio de una actuación judicial y del sistema probatorio introducido por los españoles. De lo contrario, ninguno de sus actos sería válido, pudiendo ser impugnados tanto por las autoridades seculares y eclesiásticas como, también, por quienes integraban el pueblo. Fuese primero por imposición y luego como una manera de adaptación a las nuevas 
circunstancias, lo cierto es que los interesados en acceder a la categoría de cacique respetaron y utilizaron, para su propio beneficio, el derecho indiano, mediante esta práctica judicial. Incluso más, la participación activa tanto de caciques como también de los "indios comunes" en los procesos judiciales para la obtención de una sentencia o actuación judicial favorable a sus intereses puede interpretarse como la creación de un sistema legal de consenso (Cutter 1991: 23, Cordero 2017), toda vez que el solo hecho de que los indios fueran parte del proceso constituye un aporte indígena al mismo, pues contribuye a dar forma al sistema judicial y legal del período colonial.

Ahora bien, una vez en la Real Audiencia, esta solicitaba que el o los interesados, por sí, o mediante representantes, concurrieran a Santiago a exponer los argumentos que "validaban" la solicitud de cacicazgo. Este plazo dependía de la tabla de emplazamiento, es decir, estaba de acuerdo con la distancia que mediaba entre un pueblo y Santiago. Así, por ejemplo, el plazo para que los postulantes del pueblo de Huasco concurrieran ante la Audiencia era de 90 días.

Es muy posible que durante un buen tiempo se hayan presentado falsos postulantes, o bien que una vez presentada la solicitud estos abandonasen el procedimiento. Lo anterior provocaba una demora en la tramitación de otras causas, y una pérdida de tiempo para todos quienes debían llevar adelante este tipo de actuaciones judiciales. Es por ello que, la Audiencia de Santiago, al citar a los postulantes, agregaba un apercibimiento que indicaba:

“...con apercibimiento, que sin más citarle, ni oírles se les señalaran los estrados con quienes se entenderá el ulterior progreso, y determinación de esta causa, y las providencias que se dieren; y todo lo cual ejecutare ipso pena de nuestra merced y de doscientos pesos de a ocho reales, sin excusa ni pretexto alguno, y se os declarara incurso constatando de vuestra inobediencia..."

(AHNCH, RA, 1697, 6, 196v)

A su vez, mediante este apercibimiento, la Audiencia daba realce e importancia al nombramiento de cacique, pues no se trataba, evidentemente, de cualquier tipo de actuación judicial. Por el contrario, a los oidores les correspondía refrendar una costumbre indígena, y corroborar al legítimo pretendiente al cacicazgo, futuro líder y mediador entre los indígenas y la Corona.

Podía ocurrir que solo se presentara un postulante que acreditaba su idoneidad y legitimidad para el cargo, sin que hubiese oposición o contradictor al mismo. En tal caso, la gestión judicial era de carácter no contencioso, es decir, que no existía conflicto o debate en el procedimiento. La Audiencia procedía entonces a verificar la información y, de ser cierta, solo le quedaba reconocer y refrendar al interesado como cacique.

Pero también podía ocurrir que, presentados los antecedentes por el postulante, paralelamente otros se disputaran el cargo, o bien fuese puesto en tela de juicio la capacidad, costumbres, legitimidad o validación de dicho pretendiente al cacicazgo. En este caso, el procedimiento pasaba a ser contencioso, ya que se evidenciaban intereses contrapuestos que necesariamente reflejaban la existencia de un conflicto.

Lo anterior ponía de manifiesto que aquellos que pretendían ser reconocidos como caciques incorporaron las formas jurídicas hispanas para hacer valer su derecho. Es decir, para mediados del siglo XVII en las zonas rurales de Vallenar, Copiapó, Santiago, Lampa, Rancagua o San Fernando, los indígenas comprendieron que no era suficiente tener el derecho legítimo para ser jefe de la comunidad, sino que era forzoso contar con la validación de la Audiencia, confluyendo así en este procedimiento el derecho indígena y el hispano. Más aun, "al hacerlo, contribuían de manera activa en la creación del siempre cambiante derecho indiano (y, por extensión, en la elaboración de la hegemonía consensual)" (Cutter 1991: 22, Zuñiga 2013: 2). En buenas cuentas, los pretendientes a caciques, al utilizar la maquinaria hispana para hacer valer su expectativa, estaban prestando su consentimiento al sistema foráneo, lo que, a su vez, necesariamente debió influenciar la cultura legal. (Cutter 1991: 23)

El cacicazgo se obtenía entonces, generalmente, por linaje, sin perjuicio de que en ocasiones ello no bastó, pues el pretendiente a cacique debía comprobar que estaba vinculado a la comunidad, y, en definitiva, que era integrante activo y que tenía vínculos estrechos con la misma. O bien que contaba con los méritos suficientes para hacerse cargo del pueblo. Así podemos distinguir que de acuerdo con el derecho indígena los caciques lo eran por linaje; por habilidades o capacidad necesarias para gobernar su pueblo, o además por sistema mixto: 
esto es, por sucesión hereditaria y por demostración de aptitudes para el cargo o aceptación de la comunidad del postulante ${ }^{30}$.

Así, en el pueblo de San Rafael de Rozas, en el valle de Choapa, el cacique gobernador de Lampa -que lo era también de esta localidad-solicitó a la Real Audiencia que se reconociera a Vicente Pallante como cacique, porque " ... en falta de propietario que falleció sin sucesión y lo han aclamado los naturales de su pueblo, en su virtud ocurro a US para que lo confirma con sus solemnidades de estilo dándole el título de tal..." (AHNCH, RA, 2344, 4, 36). La estrategia utilizada por el indígena gobernador para acelerar el nombramiento fue indicar que constituía un abuso que Choapa, distante a más de 80 leguas, estuviese subordinado a Lampa, lo que implicaba "...un entorpecimiento y demora en los reclamos de aquellos infelices..." (AHNCH, RA, 2344, 4, 128v). Daba cuenta, de esta manera, de que no era posible ejercer autoridad o gobernar tan amplio territorio que contaba, solo en Choapa, con 920 personas. Más aún, hizo notar que el gobierno de varios pueblos era "contra la práctica corriente que cada pueblo sea independiente y libre contra toda razón...".

Aun así, en ciertas ocasiones, lo anteriormente descrito no fue suficiente. En efecto, en 1789 Pascual Huamillen postuló al cargo de cacique, luego que en el pueblo de Copequén, valle de Colchagua, se anunciara su vacancia y se convocara a la presentación de los interesados. Pascual expresaba en su oposición de antecedentes que era hijo legítimo del anterior cacique, don José Huamillen, y doña Margarita Fuentes, y que le correspondía “...la sucesión... como hijo primogénito del difunto por tanto que se le pueda librar el correspondiente título de cacique". (AHNCH, RA, 2736, 2, 31)

Pascual Huamillen, si bien efectivamente era hijo del anterior cacique, lo era como segundo heredero, por lo que solicitaba el cacicazgo debido a que el real primogénito, Patricio Huamillen, se encontraba de peón en la estancia La Punta, de propiedad de don Lorenzo Gutiérrez, vecino al pueblo. No obstante, al enterarse Patricio que su hermano había reclamado para sí el cacicazgo, se opuso y solicitó el reconocimiento del estatus de cacique.

La Audiencia de Santiago se enfrentaba a un conflicto, pues se trataba de la solicitud presentada por dos hermanos que alegaban ser herederos legítimos del cacicazgo. Por ello, es que ordenó al subdelegado de San Fernando que remitiera las actas de bautismo de los hermanos. Paralelamente, Patricio hizo llegar a la Audiencia la información relativa a "sus costumbres e idoneidad para obtener el empleo de cacique del pueblo" (AHNCH, RA 2736, 2, 60) presentando a Guillermo Guentecura, indio, del partido de Santa Cruz de Triana, como testigo. Este señalaba de Patricio Huamillen:

“...que ha tiempo de veinte años conoce al que presenta por testigo, y que con este práctico conocimiento sabe, y le constan sus buenas costumbres, genio pacífico, y domable entre los suyos; y que asimismo, lo juzga con bastante aptitud para el gobierno del pueblo que solicita..." (AHNCH, RA, 2736, 2, 60).

A su vez, declaraba a favor de Patricio Huamillen, Alejandro Marchan, español, vecino del pueblo de Copequén, quien también lo conocía desde hacía veinte años, cuestión relevante, puesto que los testigos debían dar fe de conocerlo, pero además de que tenía las aptitudes y condiciones para ser cacique, las que indicaba claramente al señalar:

“...que harán veinte años poco más o menos que lo conoce, con este motivo saber y le consta arreglada conducta y proceder; siendo por esto querido y estimado de todo aquel vecindario: y por consiguiente lo conceptua con la idoneidad necesaria para obtener el cargo de cacique que pretende del referido pueblo..." (AHNCH, RA, 2736, 2,61)

En el mismo tenor declaraba José Madrid, español, vecino del valle de Guacarhue:

“...Dijo que conoce a dicho Patricio Huamillen por tiempo de doce años, y que en el referido tiempo no ha oído la mera expresión que sea ofensiva a su arrojado proceder, antes bien le consta que amado de todos por su genio dócil y benigno: que por lo respectivo a su idoneidad le parece sobre desempeño de su gobierno, pues lo conceptua bastante apto para ejercerlo..." (AHNCH, RA, 2736, 2, 61)

Patricio Huamillen entendía que no bastaba con ser pariente del cacique anterior, pues además debía 
probar varias circunstancias para acceder al cargo, sobre todo la buena fama. Más aún, en este caso, tratándose de una actuación judicial contenciosa, en la que había intereses en conflicto.

Nuevamente se manifiesta la irrupción del derecho hispano y su recepción por parte de los indígenas. Ello porque si bien se respetó e incorporó el derecho indígena a la elección de caciques, la Corona (Recopilación de Leyes de Indias 1681: $1,4)$ exigió que todo aquel que quisiera validar su estatus debía acreditar "buena fama", concepto entendido como "noticia o voz común de alguna cosa" (Diccionario de la Real Academia Española 1732: III). De tal forma que, en relación con la fama de un sujeto, se hacía alusión a la reputación del mismo, la que podía ser buena o mala, constituyendo un "producto derivado del sistema de honor que establecía categorías sociales y reputación en virtud de la opinión pública... "Se trata de una construcción moral basada en la disciplina social del grupo. Incluyendo reglas de comportamiento y de distribución de premios y castigos al margen del sistema judicial, aunque a veces en cooperación con él" (Herzog 1995: 266, Salinas 2000: 257).

Así, la fama, para la validación de caciques, incluía las categorías de buena conducta, estimación por el cuerpo social, idoneidad, buenas costumbres, buen genio, capacidad de comprensión a los futuros gobernados, entre otras, condiciones que a un pretendiente a cacique lo validaban ante las autoridades reales y ante los indígenas. Por ello es por lo que estratégicamente Huamillen presentó testigos que favorecieran sus intereses. Aunque llama la atención que solo uno de ellos fuese del mismo pueblo, y se tratase de un español, Alejandro Marchan. En cuanto a José Madrid y Guillermo Guentecura, si bien eran de la misma provincia, vivían varios kilómetros al sur.

Pues bien, hay que tener presente que la prueba testimonial fue considerada, en su época, como una de las más importantes, y constituyó la más frecuente clase de prueba (Murillo 2004: II, 141), ya que no bastaba la sola declaración del demandante, demandado, denunciante o interesado: era forzoso contar también con testimonios que reafirmaran lo declarado por el solicitante, para así evitar incurrir en errores judiciales o falsas acusaciones. En tal sentido, las Partidas señalaban:

"Testigos son hombres o mujeres que son tales, que no se pueden desechar como pruebas; que presentan las partes en juicio para probar las cosas negadas o dudosas, y nace gran provecho de ellos porque se sabe la verdad por sus testimonios, que en otra manera sería muchas veces escondida" 31 (Partida III, Tit.XVI, ley 1)

Más aún, en las actuaciones judiciales tendientes a llenar las vacancias de cacicazgo se constata que contaron con a lo menos dos testigos, sin estos no era posible dar fe de las competencias y habilidades del postulante. Dicho de otro modo, generalmente las declaraciones de los interesados, demandantes o demandado debían concordar unas con otras, de tal forma que los testimonios viniesen precisamente a ratificar lo aseverado. Asimismo: “... porque un solo testigo fácilmente puede declarar en falso, ya sea por error, ya por malicia" (Murillo 2004: II, 147). De ahí que se exigieran a lo menos dos testigos de buena fama ${ }^{32}$ (Partida III, Tit. XVI, ley 32).

Para que el testimonio fuese considerado plena prueba, la legislación indiana consideraba que se requerían, a lo menos, dos testigos presenciales, idóneos y contestes ${ }^{33}$ (Partida III, Tít. XVI, ley 11 y 35) Así pues, los testigos de oídas o no presenciales podían ser desvirtuados por las partes. No obstante, tratándose de procesos cuyos testigos fuesen solo indígenas, se exigió la presentación de más de dos testimonios, debido a la pusilanimidad, inconstancia y mendacidad que se adjudicaba a los indígenas (Murillo 2004: II, 149; Solórzano y Pereira 1972: II, 28, 36 425). Es más, según ordenanza del virrey Francisco de Toledo, se disponía que: “...en las causas graves donde fuere forzoso examinar testigos, no se reciban menos de seis, y esos juntos, o de por sí, depongan y declaren lo que supieren..." (Solórzano y Pereira 1972: II, 35, I 494).

La obligación de decir la verdad era fundamental para el desarrollo del proceso, porque sobre la base de los testimonios se lograba establecer si el postulante al cargo de cacique era idóneo o no. De ahí que, al momento de tomarles juramento a los testigos, el tribunal tenía la obligación de advertirles que en caso de que no dijesen la verdad, estaban cometiendo el delito y pecado de perjurio, lo que conllevaba penas severísimas que serían impuestas por el mismo tribunal.

Sumado a ello, el Derecho Indiano contemplaba como principio que no se diera crédito al testigo que deponía sin juramento. Por tanto, los indios debían cumplir con la formalidad establecida en 
el procedimiento, ya que, de lo contrario, su declaración carecía de valor (Solarzano y Pereira 1972: II, XXVIII, c. 34, 425). En otras palabras, era necesario y forzoso el juramento, porque si no se otorgaba, "no prueba la declaración ni hace fe contra otros" (Murillo 2004: II, 150). En todo caso, tratándose de los indios, el sistema procesal contempló la posibilidad de que el juez, en virtud de la discrecionalidad o arbitrio judicial con que contaba, no tomase juramento al indígena, para:

“... no ponerles en ocasión de que se perjuren, por la poca firmeza, y estabilidad de su juicio, y deposiciones, y por las sospechas que siempre tendremos en ellas de falsedad..., no obstante se recibe el juramento tratándose de causas muy graves, y que no se puedan definir de otra suerte" (Solórzano y Pereira 1972: II, XXVIII, c.34, 425)

De ahí que Patricio Huamillen presentara a dos españoles, pues sabía que el testimonio de estos tenía mayor credibilidad que el de los indios. No obstante, si era cierto lo que depusieron los testigos, esto es, que era apto para el cargo, buen vecino e idóneo para representar a su pueblo, ¿Por qué no recurrió a los indígenas del pueblo?

Seguidamente, en el proceso se consigna que las actas de bautismo de los hermanos Huamillen no fueron encontradas. Una vez más, Patricio, de manera precisa y estratégica, acompañó declaraciones de testigos que daban cuenta que junto con su hermano habían sido bautizados. Entre ellos, el testimonio de José Araya, español, natural de la doctrina, quien además era su padrino, y quien depuso que efectivamente habían sido bautizados por el teniente de cura don Antonio, de la parroquia de Río Claro.

Tal información no fue suficiente para la Audiencia, la que, al no contar con el libro bautismal con las partidas referidas, solicitó rindiera información el teniente de cura del pueblo de Olivar, distante a 16 leguas de Copequén. Pese a que el cura era de otro pueblo, lo cierto es que se encontraba en la zona desde hacía cuatro años, correspondiéndole a él visitar los diversos pueblos que integraban la doctrina. Fue en ese momento cuando se produjo un vuelco importante en el proceso, porque el fray Agustín Galves, de la orden agustina, declaró:
“...Dice que teniendo noticia que ordena su US. A mandar a pedir su fe de bautismo de Patricio Huaguillen y Pacual Huaguiillen su hermano para el fin entregarles el bastón de cacique que por derecho les toca, y constándome por la experiencia que de los dichos tengo como teniente de cura que ha sido en ese lugar mas de cuatro años ser estos unos sujetos incapaces de obtener dicho empleo por sus enormes hechos y desacreditada conducta, y que gobernando el pueblo estos se siguen graves daños y escándalos como que desde que entre a este lugar diariamente he amonestado a las justicias con mis continuas querellas que a los dichos he puesto, y para que cumplan con la ley ... y aun siendo así el mencionado Pascual más de dos años que no se confiesa, y aun estando como ha estado gobernando dicho pueblo, y diciendo dar ejemplo ha sido el más escandaloso desobedeciendo contrariamente a los mandatos ... viviendo continuamente con notable escándalo de las gentes amancebado más de seis años con una mujer del valle nombrada Petrona González la que ha mandado poner en depósito para separarlo de tan perniciosa amistad... más de esto se halla Teodora Sotelo cuñada del referido actualmente en depósito por estar viviendo malamistado con ella..." (AHNCH, RA, 2736, 2, 31).

Pero eso no era todo, pues el cura indicó, asimismo, que los hermanos jamás asistían a misa, "que insultan a la iglesia y al mismo tiempo al cura, cuando este realiza prédicas al aire libre". Insolencias que a juicio del sacerdote eran irreproducibles. Con la intención de contrarrestar a los hermanos, los amenazó con la pena de excomunión. Sin embargo, estos indios, junto con otro de sus hermanos llamado Agustín, se mofaron de la misma. Seguidamente acusó a todos los hermanos Huamillen de públicos ladrones y ebrios, y que "poco respeto tienen por los demás indios". Indicaba que el cura de Nancagua "puede dar fe de sus dichos", porque se trata de hechos públicos y notorios.

Bajo tales acusaciones no era posible nombrar, ni siquiera como interino, a uno de los hermanos Huamillen. Es más, el fiscal de la Audiencia declaraba: 
“... en virtud de lo que resulta de la información recivio la carta que en debida forma presenta del Padre Fray Agustín Galvez religioso de la orden de San Agustín y vice párroco de la doctrina de Olivar en el que le informa que el nominado Patricio, y su hermano Pascual Hualligén son incapaces de obtener el empleo de cacique por sus perversas costumbres y pésimos procedimientos de que se refiere varios pasajes que asegura constarle con motivo de haber servido aquella parroquia el tiempo de más de cuatro años; y teniendo esta relación a su favor la presunción de verdadera por ser precedida de un sacerdote que tiene las veces de párroco en la enunciada doctrina a la que pertenece el pueblo de Copequen, no le parece oportuno sea provea el cacicazgo hasta que se esclarezca de todo punto la verdad de la conducta y procedimiento de Patricio..." (AHNCH, RA, 2736, 2, 67)

Claramente, la información entregada por el teniente de cura generaba más incertidumbres y dudas respecto de la idoneidad de los hermanos para asumir el cargo de cacique. Es por ello que se recibió la información del capitán Joseph Vithorino de Villalón, quien por un tiempo hizo las veces de juez diputado de la zona y, como tal, conoció varias querellas por robos, las que fueron probadas y remitidas al subdelegado. A su vez, el teniente de caballería Sebastián Guzmán, conteste con Villalón, indicó que el diputado Nicolás Varela tuvo presos a los hermanos Patricio y Pascual. Asimismo, que a dicho diputado le correspondió aplicar la pena de azotes a los hermanos por ebrios, ladrones y amancebados. Incluso, Guzmán señaló que era público que en sus casas "...se aposentan toda clase de bellacos, hay ladrones y amancebados" (AHNCH, RA, 2736, 2, 71); agregaba, además, que, siendo vecinos del pueblo, se experimentaron varios robos.

Esta información era complementada por Francisco Zúñiga, español, e Isidro Garay, quienes indicaban que en casa de los caciques vivían Joseph Damasio Osorio, Pascual Urra y Luis Guagilen, todos conocidos ladrones que a pie habían escapado de la provincia de Rancagua. Más aún, que eran perseguidos por la justicia eclesiástica y la secular (AHNCH, RA, 2736, 2, 74).

Se trataba de un asunto grave y complejo. Grave porque se imputaban malas costumbres y actuaciones delictuosas a los aspirantes a cacique, que además eran de carácter público y notorio. Y complejo, porque de no ser ciertas las denuncias, se estaba descalificando y excluyendo a los legítimos pretendientes al cargo. Más aún, porque tras las acusaciones podía haber viejas rencillas o vendettas entre los involucrados que solo pretendían entorpecer el camino para finalizar la vacancia.

Ante estas aprensiones, se tomó la declaración de don Manuel Sánchez “... hombre de muy acreditada conducta...", a quien le correspondió administrar "la real vara de la justicia", quien sin titubear indicó que le correspondió juzgar y aplicar las penas contra los hermanos, entre ellas la de restituir novillos, caballos y otros animales. Asimismo, que tuvo preso a Pascual por su "andar escandalosamente con Petrona González", que le consta que son todos ebrios y "...siempre perseguidos por la justicia secular y eclesiástica" como, también, que se trata de individuos "...que andan descomulgados" (AHN, RA, 2736, 2, 75, 75v).

La información fue suficiente para descartarlos como posibles candidatos, porque:

“...se ha justificado y comprobado suficientemente la denuncia que se hizo en la carta de F.20 contra los procedimientos de los indios Pascual y Patricio Guagillen a presencia de ella no parece justo proceso por ahora al cacicazgo asi ninguno de los dos; entre tanto no purgan y reforman sus malas costumbres; porque si se confirma este cargo a alguno de ellos sin que constare positivamente su enmienda, sería de pésimo ejemplo para los indios a quienes debe gobernar..." (AHNCH, RA, 2736, 2, 77).

Más aún, porque la Audiencia de Santiago entendía que el cargo de cacique implicaba ser juez natural del lugar. Ello obligaba entonces a buscar un buen candidato que fuese idóneo, pero, además, legítimo entre sus congéneres.

\section{Conclusiones}

El que la Corona española permitiera la pervivencia del cacicazgo, en el período colonial, obedeció a razones estratégicas, políticas y culturales. En efecto, "el cacique" se constituyó en la institución jurídica indígena más importante porque mediante ella fue posible ejercer control social, mediar entre 
los diversos pueblos de indios y las autoridades reales, como también dar algún grado de estabilidad y continuidad a los diferentes sujetos indígenas que se vieron impactados y desestructurados por efecto de la conquista y colonización hispanas.

Así, al contar con articuladores políticos y culturales, legítimos en cuanto eran elegidos conforme con la tradición jurídica indígena, y validados por la Corona para que pudiesen ejercer el poder de gobierno al interior de sus comunidades, fue posible negociar consensos tendientes a incorporar a los indígenas al nuevo "orden" que se impuso desde la Conquista.

En todo caso, y pese a la imposición de nuevas categorías y significaciones políticas, jurídicas y sociales, al adaptarse a las nuevas circunstancias, los indígenas recrearon las formas jurídicas y políticas coloniales. El derecho indiano recogió y reconoció la tradición jurídica precolombina, con lo que se vio enriquecido e influenciado mediante este. Pero ello no es todo. Quienes tuvieron el estatus de cacique-generalmente por linaje, pero también por méritos o sistema mixto- supieron traducir el sistema hispano a su propia realidad cultural, lo que les permitió adaptar y traducir la maquinaria jurídica hispana para acceder al cargo y, además, manipularla y utilizarla convenientemente para sus intereses y pretensiones.

En buenas cuentas, la utilización constante y permanente, por parte de los interesados o pretendientes a caciques, del sistema judicial para el reconocimiento de su estatus, prueba la capacidad y habilidad adaptativa de este grupo colonial a las nuevas circunstancias. En efecto, supieron comprender la necesidad de validarse mediante prácticas judiciales, lo que implicó legitimar el sistema institucional indiano y, además, mediante ello fue posible establecer espacios de negociación que permitieron la conservación de sus tierras y ciertas actividades cotidianas que no fueran contrarias al orden que se imponía desde la Corona.

\section{Agradecimientos}

Este artículo es parte de una investigación realizada gracias a la beca de "Investigación" otorgada por el Max-Planck Institute for European Legal History, Frankfurt am Main (2016).

\section{Referencias Citadas}

Aldunate, Carlos

1984 "El cacicazgo en el Reino de Chile. Siglo XVIII", en Boletín de la Academia de la Historia de Santiago, 95, pp. 169-212.

Carvallo y Gocheneche, Vicente

1875. Descripción Histórica Geográfica del Reino de Chile, Imprenta de la Librería del Mercurio, Santiago.

Conteras, Hugo

1998 "Los caciques de Talagantes durante el siglo XVIII. Legitimidad, prestigio y poder. 1718-1791", en Cuadernos de Historia, Departamento de Ciencias Jurídicas, Políticas y Sociales, Universidad de Chile, pp. 139-167.

Cordero, Macarena

2014 "Precariedad del proyecto disciplinador de la Corona e Iglesia en el siglo XVIII: las doctrinas periféricas de la diócesis de Santiago de Chile", en Rafael Gaune y Verónica Undurraga (eds.), Formas de Control y disciplinamiento en Chile, América y Europa, siglo XVI-XIX, Ed. Uqbar, Instituto Riva Agüero, Santiago, pp. 143-166.

Cordero Fernández, Macarena,

2017 "Reproducción y traducción de la cultura judicial hispana en el imaginario indígena. Chile, Siglo XVII y XVIII". Revista Estudios de Historia Novohipasna, № 57. 2017. 8-26.

Covarrubias, Sebastián de

1611 Tesoro de la lengua Castellana o Española, impresor Luis Sánchez, Madrid.
Cutter, Charles

1991 "El indio fronterizo ante la justicia española: la creación de una hegemonía consensual", en IX Congreso del Instituto Internacional de Historia del Derecho Indiano, Ed. de la Universidad Complutense de Madrid, Madrid, pp. 19-28.

De Bibar. Gerónimo

1966 Crónica y relación copiosa y verdadera de los Reynos de Chile [1558], ed. Facsimilar, Fondo Histórico y Bibliográfico Toribio Medina, Santiago.

De Ramon, Emma

2004b "La incorporación de las etnias no hispanas a la actividad industrial durante la colonia temprana", en Revista del Archivo Nacional, 2, pp. 42-47.

Díaz, Carlos

1977 "El cacicazgo en el Virreinato del Perú", en Estudio Histórico Jurídico, Universidad de Sevilla, 18.

Góngora y Marmolejo, Alonso de

1864 Historia de todas las cosas que han acaecido en el reino de Chile y de los que lo han gobernado [1576], Imprenta del Ferrocarril, Santiago.

Herzog, Tamar

1995 La administración como fenómeno social: la justicia penal de la ciudad de Quito (1650-1750), Centro de Estudios Constitucionales, Madrid.

Hidalgo, Jorge

2004 Historia Andina de Chile, Ed. Universitaria, Santiago. 
López de Tovar, Gregorio

1555 Las Siete Partidas del sabio Rey don Alonso el Nono nuevamente glosadas. Salamanca.

Mariño de Lovera, Pedro

1865 Crónica del Reino de Chile, Imprenta del Ferrocarril, Santiago.

Murillo, Pedro

2004 Curso de derecho canónico hispano e indiano, Alberto Carrillo (trad., ed.), Colegio de Michoacán-UNAM, Zamora, vol. II.

Pietschmann, Horst

1990 "Consideraciones en torno al problema del estudio del derecho indígena", en IX Congreso del Instituto Internacional de historia del derecho indiano. Actas y estudios, Ed. Universidad Complutense de Madrid, Madrid, pp. 7-17.

Recopilación de Leyes de Indias.

1998 [1681] ed. facsimilar, Centro de Estudios Políticos y Constitucionales y Boletín Oficial del Estado, Madrid.

Real Academia Española

Diccionario de la Lengua Castellana, T. II, Madrid, Imprenta de Francisco del Hierro, 1729.

Real Academia Española

Diccionario de la Lengua Castellana, T. IV, Madrid, Herederos de Francisco del Hierro, 1734.

Ruiz, Enrique

1916 La Magistratura Indiana, Imprenta de Coni Hermanos, Buenos Aires.

Salinas, Rene

2000 "Fama pública, rumor y sociabilidad", en Lo público y lo privado en la historia americana, Fundación Mario Góngora, Santiago.
Silva, Fernando

1962 Tierra y pueblos de indios en el reino de Chile. Esquema histórico jurídico, Facultad de Ciencias Jurídicas, Políticas y Sociales, Universidad Católica de Chile, Santiago.

Solórzano Pereira, Juan de

1972 Política Indiana [1648], Biblioteca de Autores Españoles, Madrid.

Tau, Víctor

1970 "La costumbre como fuente del derecho indiano en los siglos XVI y XVII. Estudio a través de los Cabildos del Río de la Plata, Cuyo y Tucumán", en III Congreso del Instituto Internacional de Historia del Derecho Indiano, Instituto Nacional de Estudios Jurídicos, Madrid, pp. 115-192.

Valenzuela, Jaime

2010 "Indígenas andinos en Chile colonial: Inmigración, inserción espacial, integración económica y movilidad social (Santiago, siglos XVII-XVII)", en Revista de Indias, vol. 70, 250, pp. 749-778.

Zorrilla, Enrique

1942 Esquema de la justicia colonial en Chile, Universidad de Chile, Santiago.

Zúñiga, Jean P.

2013 Negociar la obediencia. Autoridad y consentimiento en el mundo ibérico en la Edad Moderna, Comares Historia, Granada.

\section{Fuentes}

Archivo Histórico Nacional de Chile, Fondo Capitanía General, Santiago (AHNCH, CG), vols. 531, 1761.

Archivo Histórico Nacional de Chile, Fondo Real Audiencia, Santiago (AHNCH, RA), vols. 1603, 1697, 1768, 1789, 1817, 1949, 2146, 2344, 2736.

Notas

1 Las prácticas judiciales las entiendo como aquellas actuaciones judiciales que constituyen representaciones y prácticas sociales y culturales de los sujetos que intervienen en un proceso judicial. Para más detalles, ver Cordero Fernández (2017)

2 En sentido similar, Díaz (1977) y Aldunate (1984: 179).

3 Respecto de la asimilación del estatus de cacique al de mayorazgo véase la investigación desarrollada para el virreinato del Perú, de Díaz (1977: 97) Asimismo, para el caso del Reino de Chile, ver: Archivo Histórico Nacional, Fondo Capitanía General, Bernardo Cárdena. Encomienda de Mendoza. 1708. vol. 481, fojas 253-265v, en el que se da cuenta de esta asimilación.

4 Jorge Hidalgo en sus investigaciones ha logrado probar que, durante el período precolombino, en las culturas que habitaban los valles de Copiapó, Huasco, Coquimbo, Limarí y Aconcagua coexistían autoridades locales con centros administrativos incaicos. Las autoridades locales estaban organizadas de manera similar al patrón andino de la dualidad, esto es, que cada espacio estaba dividido en dos, la zona costera (baja) y la zona cordillerana (alta), gobernada cada una por una autoridad indígena que mantenía relaciones de amistad y cooperación entre ellos. Hidalgo (2004:30-31)). Respecto de los valles y espacios al sur del Cachapoal, la documentación colonial de las primeras décadas refleja una organización menos estructurada y jerarquizada que la zona norte chilena, que se traduce en que los líderes eran elegidos por sus méritos, más que por razones genealógicas. Véase de Bibar (1966 [1558]).

5 En efecto, para el caso de Chile los cronistas utilizaron el concepto cacique para hacer referencia a los jefes locales. Góngora Marmolejo (1864:22) señala: "Muchos caciques y hombres principales tratan entre ellos, juntos como estaban, qué orden tendrían para pelear con los cristianos...". Por su parte, Pedro Mariño indica: "Viendo los indios, que guiaban a estos españoles, que no habían hallado al ejército, que decían, dieron aviso al gobernador llamado Anien, y aun cacique..." (Mariño de Lovera 1865). A su vez, Vicente Carvallo Goyeneche (1875) en diversas partes de su descripción hace alusión al concepto de caciques. En el mismo sentido la Recopilación de Leyes de Indias (1998 [1681]: II, 245) que indica: "Algunos naturales de las indias eran en tiempos de su infidelidad Caciques, y señores de sus pueblos, y porque después de su conversión a nuestra Santa fe Católica, es justo que conserven sus derechos...". En sentido similar, Aldunate (1984: 180).

6 El proceso de indianización consistió en que las poblaciones originarias de América fueron identificadas política y jurídicamente por la Corona como una unidad: "indios", "pueblos de indios", "república de los indios", sin distinción 
de las diferencias étnicas, culturales, políticas, sociales, etc., que existían entre ellas. Lo anterior implicó que la creación de instituciones y legislación para estos grupos fuese de carácter homogéneo y general, sin atender a los rasgos específicos de cada etnia. Sin embargo, ello no significó que se obtuviera de este proceso una identidad única "india" americana. En efecto, durante el siglo XVI se dio un proceso de indianización, que significó que los diversos grupos étnicos se incorporaron a la república de indios. Sin embargo, para la centuria siguiente es posible observar, en algunas regiones, un progresivo proceso de desindianización, ya que se constata la pervivencia o rescate de antiguas dinámicas culturales. Lo anterior como resultado de una política más laxa de la Corona hacia los diversos espacios bajo su dominio. Así, para el siglo XVIII, la política borbónica tendiente a "Reconquistar" América consideró revitalizar el proceso de indianización con el objetivo de facilitar la hispanización, entendido esto como un proceso que trató de homogeneizar, uniformar y reglamentar el universo simbólico de los indígenas mediante el sistema sociocultural hispano, elemento que constituiría el identitario con los conquistadores, debido a que erradicaría las singularidades culturales e históricas de los pueblos originarios.

7 En el mismo sentido, ver: Cutter (1991: 18-28)

8 En efecto, entre las atribuciones dadas a los caciques se describen claramente por la real Audiencia la de lograr que sus pueblos vivan en armonía y cristiandad, ejerciendo así control social sobre la población. Véase: Archivo Histórico Nacional, Fondo Capitanía General, vol. 530, pieza 5, 1761, fs. 29. Juan de Balmaceda por el indio Bartolomé Cortalién. Acerca del título de Cacique del Pueblo de Sotaquí: “...y que al uzo y ejecucion de el dicho oficio no os pongan ni consientan poner impedimento ni embarazo alguno que nos por la presente os havemos por recivido y tendreis grande cuidado con los yndios de dicho pueblo hasiendoles que en los dias asignados rezen la doctrina Christiana y vivan sociablemente sin permitir que en dicho Pueblo Recidan españoles mestizos mulatos ni sambaygos so pena de que se procedera contra vos".

9 La voz Gobernador es entendida de acuerdo con el Tesoro de la Lengua Castellana (1611: 36-37) y el Diccionario de la Real Academia Española (1734: IV) como: el que dirige, y encamina alguna cosa, para lograr el fin que desea. Que puede ser la República, o personas o un negocio particular.

10 En efecto, la Recopilación de leyes de los Reynos de las Indias, indica Lib 6, Tít. 7 ley 3: "Desde el descubrimiento de las Indias se ha estado en posesión y costumbre, que en los cacicazgos sucedan los hijos a sus padres: Mandamos que en esto no se haga novedad, y los Virreyes y Audiencias, y gobernadores no tengan arbitrio en quitarlos a unos, y darles a otros, dejando la sucesión al antiguo derecho, y costumbre". En buenas cuentas, la legislación reconoció la sucesión hereditaria, así como también todas las formas de autogeneración de autoridades que probadamente fuesen parte de la tradición indígena, y no contraviniesen la moral y las buenas costumbres, cuestión que se condice con el carácter pragmático y casuístico del Derecho Indiano. Véase (Tau 1970: 115-192)

11 La voz Gobierno es entendida como el modo de regir y ordenar el superior los inferiores (Tesoro de la lengua
Castellana 1611: 36 y 37), (Diccionario de la Real Academia Española 1734: IV).

12 Podía suceder que un pueblo tuviese gobernador y no cacique, y viceversa, pues no era forzoso que confluyeran en una persona ambas calidades. En todo caso, para el virreinato del Perú, Díaz (1977: 42) señala que podía ocurrir que en un pueblo no hubiese cacique y sí gobernadores, situación que "se daría principalmente en las poblaciones que carecían de caciques de sangre".

13 Carlos Aldunate considera que los gobernadores son los caciques interinos, debido a que en ausencia del cacique de su pueblo eran quienes gobernaban a la población. A su vez, indica que no utilizaban el título de don, pues estaba reservado para el propietario, pudiendo ser removidos en caso de no desempeñar bien sus funciones o tener malas costumbres (Aldunate 1984: 189-190). Si bien muchas veces los caciques interinos fueron a la vez gobernadores, lo cierto es que la calidad de gobernador no implicaba necesariamente ser una autoridad provisoria; por el contrario, el estatus de gobernador implicó la capacidad de gobierno que siempre tuvo el cacique propietario, como también podía recaer en el interino, según fuese el caso.

14 En efecto, conforme con la documentación conservada en el Archivo Histórico Nacional, se puede concluir que la mayoría de los caciques fueron también gobernadores. Lo anterior se dedujo a partir de la manera en que los expedientes consignan la diversidad de estatus. Así, en aquellos documentos en que solo se indica el término cacique sin distinción alguna, estamos en presencia de un cacique gobernador. De lo contrario, las diversas autoridades hispanas, así como también quien ejerce de gobernador hacen alusión a bajo qué cargo está actuando, indicando que es solo gobernador o cacique interino. En buenas cuentas, si estamos en presencia de un gobernador o interino, se trata de una autoridad que ejerce gobierno, pero que carece del estatus de cacique, y, en consecuencia, de todos los derechos y prebendas de esta institución.

15 Tal es el caso de Luis Lebiguañilen, quien al ser validado como cacique, expresamente se indicó por la Audiencia que era además gobernador “...para que como tal atienda, al mayor bien y conservacion de los yndios, de el y que esten reducidos en su origen, y naturalessa, vien ynstruidos y enseñados en los misterios de nra Sta fee y que acudan a los exercicios christianos, con puntialidad, y cuidado y le obedescan y respeten como tal governador dando cumplimiento, a sus hordenes, y las justicias de este Reyno le tendran por governador de el dho pueblo, y haran se le guarden los fueros y preheminencias, que por ello le competen em virtud de este decreto que sirva de titulo em forma". En Archivo Histórico Nacional, Fondo Real Audiencia. "Lebiguañilen (Luis), Expediente sobre que se le nombre cacique del pueblo de indios de Copequén", vol. 1697 pieza 8 fojas 12 año 1697-1704. También en sentido similar "Ante mi Dn Gregorio de Argomedo correg.r Subalterno pr ausiensia de el propietario Dn Juan de Morande con todos los yndios pertenecientes a su pueblo de quien resibi juramento qe lo hise por Dios Ntro Señor y una señal de cruz según dro en el qual prometio obrar bien, y fielm.te en el ministerio de dho casicasgo y a bos de todos ellos admitieron, obedesieron y reconocieron $\mathrm{pr}$ tal su casique al mensionado Dn Jph Ant.o Henrriquez, y 
puse en posesion de su empleo y pa qe conste dha posesion, lo puse pr diligencia autuando por mi y ante mi y ausensia de el escribano de que doi fee (f. 68)". Archivo Histórico Nacional, Fondo Real Audiencia, con Morales Naguelquelén (Juan), sobre mejor derecho al cacicazgo del pueblo de Malloa, Henríquez (Mauricio), vol. 1763 pieza 4, fojas 25, año 1782.

16 En Pomaire, al morir el cacique, don Santiago Soriano, quedó como heredero su hijo menor de edad, don Tomás Soriano que tenía entre 10 a 12 años, por lo que se nombró un cacique interino hasta que cumpliese los 25 años. Archivo Histórico Nacional, Fondo Real Audiencia. Pomaire (Cacicazgo de), expediente sobre su provisión, vol. 1949, pieza 2. 1768 y 1769 , fs. 93.

17 Hugo Contreras (1998: 140) sostiene que los caciques eran nombrados por la Real Audiencia, pero que, asimismo, eran legitimados al interior de la comunidad por su descendencia de los antiguos caciques y las acciones que en su ejercicio desempeñaban. Nuestra investigación nos induce a aseverar que en la práctica los caciques eran legítimos de acuerdo con las condiciones que señala Contreras. Sin embargo, la Audiencia lo que realizaba era una validación del cargo, y no un nombramiento que con posterioridad se legitimaba. Por el contrario, el cacique debía probar primeramente que era un postulante legítimo; acreditado ello, era validado por la autoridad mediante su nombramiento.

18 En relación con las prerrogativas económicas que concede el cargo de cacique, véase a Aldunate (1984: 191) y Silva (1962: 23).

19 Entre ellos está el caso de Bartolomé Cuntulien, a quien se le reconoció su cacicazgo en el pueblo de Sotaquí, quien "presentó una petición diciendo que el suso dicho era hijo de don Rodrigo Cuntulien y nieto de Don Rodrigo Cuntulien, y que estos con seis demas asendientes havian sido casiques de el pueblo de Sotaqui y que los susodichos heran muertos y el dicho Don Bartholome heredero de su padre le pertenesia dicho casicasgo ofreciendo ynformacion de lo expresado, y que con vista de ella se declarase por tal casique, la que se le mandó dar con sitacion de nuestro fiscal; y dada el dicho protetor la presentó de que se dio vista al dicho Nuestro fiscal, y con lo que respondio se pidieron los autos y con vista de ellos los dichos nuesto Presidente y oidores Proveyeron un decreto que es de el tenor Siguiente: Declarase a Don bartholome Contulien por casique de el pueblo de Sotaqui sin perjuicio de dho que mexor derecho tenga y se le despache el titulo que pide en forma ordinaria". Archivo Histórico Nacional, Fondo Capitanía General, vol. 530, pieza 5, 1761. Juan de Balmaceda por el indio Bartolomé Cortalién. Sobre título de Cacique del Pueblo de Sotaquí. Sotaquí. 12/2/1761 fojas 27 y 27.

20 Tal es el caso de Buenaventura Huencho, quien reclamó en 1811 el cacicazgo porque "ser hijo legitimo de legitimo matrimonio sucesor del cacicasgo" (f. 87) "de ser primogenito hijo legitimo de el ultimo casique de el enunciado pueblo" f. 93. Archivo Histórico Nacional, Fondo Real Audiencia, vol. 1436, pieza 3, fs. 10. Huencho (Buenaventura) Expediente que sigue sobre ser declarado cacique del pueblo de Gallardo, en la jurisdicción de Melipilla.

21 Luego de la muerte del cacique de Rapel, se presentaron varios pretendientes que indicaban ser legítimos para el cargo. Ante ello, Miguel acompañó testimonios que daban cuenta de que es "de una conducta sumamente justiciera y sin vicio alguno, que no se junta con nadie ni sale de su casa, pues luego que salió del cura que lo educó pasó a casa de este declarante donde se ha mantenido trabajando con que socorría a la madre y socorre hasta el presente como a los demás hermanos... solo se inclina a lo bueno y muy aplicado a leher, como se sabe hasta escribir". Archivo Histórico Nacional, Fondo Real Audiencia, vol. 1603, fs. 12, 1783. Millaloán (Miguel), con Rapiluquén (Margarita), sobre mejor derecho al cacicazgo de Rapel, jurisdicción de Colchagua.

22 Pese a la constatación de J. Hidalgo en orden a establecer que muchos pueblos de la zona central de Chile tenían caciques por linaje desde la época precolombina, lo cierto es que, durante el período colonial, se pudo constatar que algunos de ellos contaron con caciques elegidos, a base del mérito, y no por vínculos de parentesco. La elección de caciques por méritos en la zona central de Chile se debió a la desestructuración de estos pueblos por efecto de la colonización, y por las migraciones forzadas o voluntarias de indígenas de diversas regiones del continente, lo que provocó la conformación de nuevos pueblos y comunidades indígenas. Lo anterior dio paso a la formación de pueblos integrados por sujetos de diferentes orígenes y tradiciones, que al unirse debieron recrear nuevas formas de autogobierno y organización (Hidalgo 2004). Para más detalles de las migraciones y formación de nuevos sistemas identitarios, ver: Valenzuela (2010) y De Ramón (2004b).

23 De acuerdo con los registros revisados, hubo ocasiones en que el nombramiento de cacique se hizo complejo debido a que eran muchos los pretendientes que tenían vínculos sanguíneos con el anterior cacique. Ante tales situaciones, la Audiencia de Santiago tuvo un criterio casuístico, es decir, resolver caso a caso. Así, en algunas oportunidades optó por preferir a los parientes varones más cercanos parentalmente al cacique muerto. Como fue el caso de Millaloán (Miguel), con Rapiluquén (Margarita), sobre mejor derecho al cacicazgo de Rapel, jurisdicción de Colchagua. Es más, los oidores aclararon: “... si estos edictos se pudieran tener a tal efecto, no se libraría a cada bacante o muerte de cacique la real provisión de casicasgo, sitando de nuevo a todo los interesados interesputante y bastaría solo que el primogénito del último poseedor justificare ésta calidad". Archivo Histórica Nacional, Fondo Real Audiencia, vol. 1603, fs. 16-35 y 75, 1784. Millaloán (Miguel), con Rapiluquén (Margarita), sobre mejor derecho al cacicazgo de Rapel, jurisdicción de Colchagua.

24 Así se desprende al leer el reclamo de Vicente Paillante contra la pretensión del cacique de Choapa de usurparle el cargo, al indicar: “...pueden verificarlo, sin que primero ocurriesen al de Lampa como se ve en el cuaderno presentado contra la práctica corriente que cada pueblo sea independiente y libre y contra toda razón...". Se trata de un nombramiento contrario a la costumbre local. Archivo Histórico Nacional, Fondo Real Audiencia, Paquilicuima Julián, expediente sobre su nombramiento de cacique del pueblo de indios de Huasco Alto, vol. 1697, pieza 6, fojas 16, año 1789.

25 Diccionario de la Real Academia Española (1734: IV) Voz gremio: dice también relación con "Holgó mucho el 
Papa de oír estos ofrecimientos: y como Padre piadoso abrió luego los brazos al hijo pródigo, que volvia con gran humildad al grémio de la Iglesia Cathólica", es decir, se trata de diversas personas con nexos comunes. Así también ocurrió en el pueblo de Roco, de la doctrina de La Ligua, en que muerto el cacique, se autonombró como mandón Pedro Pascual Ávila; ante ello los indígenas por medio del fiscal de la Audiencia solicitaron que se nombrase cacique “...El fiscal de S.M protector gral de los naturales del rno dice: que segun la representación que compaña subscripta por el yndio Vicente Carroza se halla vacante el casicasgo del pueblo de Roco, por la muerte del ultimo poseedor, y sus tituido en su lugar un mandon llamado Pedro Pasqual Abila, qn tiene puestos colonos en las tierras de la comunidad, y ocupada la mejor; y mayor porción de ellas en perjuicio de los naturales como lo certifica el parroco de la doctrina de Sto Domingo de Rosas. Bajo de este supuesto es nesesario remediar oportunamente estos daños, y siendo la pral causa de ellos la falta de casique convendria se libre la provicion ordinaria para que el diputado desta doctrina...". Archivo Histórico Nacional, Fondo Real Audiencia, Roco (cacicazgo del pueblo de) en La Ligua, Expediente sobre provisión de dicho cacicazgo, vol. 1763, pieza 25, fojas 134, 1792-1793.

En efecto, hay otros procesos judiciales en los que se consigna que el pretendiente a cacique ha de ser "del pueblo", esto es, haber nacido y criado en la zona que quiere gobernar, descartándose a los forasteros. Incluso, a aquellos que son hijos de afuerinos. Archivo Histórico Nacional, Fondo Real Audiencia, con Morales Naguelquelén (Juan), sobre mejor derecho al cacicazgo del pueblo de Malloa, vol. 1763, pieza 1, 1678 y vol. 1603, fs. 93, 1784. Millaloán (Miguel), con Rapiluquén (Margarita), sobre mejor derecho al cacicazgo de Rapel, jurisdicción de Colchagua.

Archivo Históricoa Nacional, Fondo Real Audiencia, vol. 1697, pieza 6, f. 191. Paquilicuima Julián, expediente sobre su nombramiento de cacique del pueblo de indios de Huasco Alto.

En el Archivo Histórico Nacional se han encontrado registros de solicitudes de los indígenas de destitución del cacique, sea esto motivado por los vicios del propietario como en el caso registrado en Archivo Histórico Nacional, Fondo Capitanía General, Fco. Molina, administracion de indios de Rapel. Solicita la remocion del cacique de Rapel. Stgo, vol. 511, pieza 9, 1761, en la que reza: "M.Y.S.P Gov.or y Cap.n Gral Dn Fran.co Molina administrador de los yndios de el Pueblo de Rapel; puesto a los pies de VS con su mayor rendim.to dise que haviendose auzentado de dho pueblo el casique principal, y no saviedose de su paradero, allandose por esta causa los yndios de dho pueblo dispersos, y repartidos en diferentes lugares, y los pocos que en dho pueblo se allavan, sin tener quien los enseñase, y diese la correc.n fraternal que es nezesaria; a pedim.to de estos fue nombrado por casique interino governador a Blas Chuli, quien en ves de sugetarlos, enseñarlos aresar y darles buen exemplo, ha hecho lo contrario y los yndios seguidole a vista de su escandalosa vida, sin que el suplicante por su parte, aya podido hacer los entrar por camino, ni a que resen como es constumbre y su obligación congregados en la capilla, dimanado de el poco zelo con que prozede el dho Blas, ... A V.S pide y suplica que habiendo manifestados los autos se sirva de mandar haser lo que fure de justicia y jura en lo necesario", fs. 123, 123v y 124. En sentido similar, Archivo Histórico Nacional, Fondo Real Audiencia, vol. 1603, 1783, fs. 1. Millaloán (Miguel), con Rapiluquén (Margarita), sobre mejor derecho al cacicazgo de Rapel, jurisdicción de Colchagua. O bien porque no es "oriundo" de la localidad, Archivo Histórico Nacional, Fondo Real Audiencia, Con Morales Naguelquelén (Juan), sobre mejor derecho al cacicazgo del pueblo de Malloa, vol. 1763, pieza 1, 1678. Es probable también que muchas de las solicitudes de destitución se hayan debido a pugnas al interior de los pueblos de indios que se zanjaron mediante la utilización del sistema judicial colonial en beneficio de un bando.

29 En el caso del pretendiente a cacique de Lo Gallardo, cercano a San Antonio del Mar: “...que se le ha presentado de Josef Joaquín Guenchu, y a puesto en sus manos la fe de bautismo que en devida forma manifiesta...". Archivo Histórico Nacional, Fondo Real Audiencia, Huenchu (José Joaquín), expediente sobre que se le ponga en posesión del cacicazgo del pueblo de San Antonio o de Gallardo, en la jurisdicción de Melipilla, vol. 1765, pieza 6, fs. 147, 1783-1784.

30 Tal es el caso del cacique de Talagante Domingo Toro, nieto del cacique Lázaro Lienlu, quien asumió como tal por vínculos parentales y por aceptación de la comunidad. En Archivo Histórico Nacional, Fondo Real Audiencia. Testamento de don Lázaro Lienleu, 29 de abril de 1746. Asimismo, Contreras (1998:148).

31 Código de las Siete Partidas, Partida III, tít. XVI, ley 1.

32 Código de las Siete Partidas, Partida III, tít. XVI, ley 32.

33 En el mismo sentido Partida III. 16. 11 y 35. 